\title{
STUDY OF THE INFLUENCE OF CONSTITUENT RATIO ON THE CROSSLINKING REACTION OF CASTOR OIL MODIFIED EPOXY RESIN BY 4.4'-DIAMINO DIPHENYLMETHANE
}

\author{
Do Minh Thanh ${ }^{1, \text { * }}$, Le Xuan Hien ${ }^{1}$, Nguyen Tien Dung ${ }^{2}$ \\ ${ }^{1}$ Institute for Tropical Technology, VAST, 18 Hoang Quoc Viet, Cau Giay, Hanoi \\ ${ }^{2}$ Faculty of Chemistry, Hanoi National University of Education, 136 Xuan Thuy, Hanoi \\ "Email: thanhnau.vn@gmail.com
}

Received: 21 September 2015, Accepted for publication: 16 March 2016

\begin{abstract}
Influence of the contents of epoxy resin modified by castor oil (ECO), 4,4'- diamino diphenyl methan (DDM) on the crosslinking reaction of ECO by DDM at $180{ }^{\circ} \mathrm{C}$ have been studied and mol ratio of $\mathrm{A} / \mathrm{E}=1$, curing time of 270 min have been determined to be the optimal conditions for formation of the cured coating having gel fraction, swelling degree, flexibility, adhesion, impact resistance, and relative hardness of $86 \% ; 188 \% ; 1 \mathrm{~mm}, 0$ point, $200 \mathrm{kG} . \mathrm{cm}$ and 0.33 , respectively.

Keywords: epoxy resin, castor oil, 4,4'- diamino diphenyl methane, curing.

\section{INTRODUCTION}

Thanks to epoxy, hydroxyl groups and double bonds, epoxy resins modified by unsaturated triglyceride vegetable oils can be chemically converted or cured by different methods [1-5]. The published research results of the Laboratory for Rubber and Natural Resins Material (LRNRM), Institue for Tropical Technology (ITT) showed that systems based on epoxy resin modified by soyabean oil and DDM can be cured at high temperature with formation of high performance coatings [5]. Therefor, DDM have been used for curing of epoxy resins modified by various vegetable oils. This work presents some results of the study of the influence of constituent ratio on the crosslinking reaction of castor oil modified epoxy resin by 4,4'-diamino diphenylmethane.
\end{abstract}

\section{EXPERIMENTAL}

\subsection{Materials}

Epoxy resin modified by castor oil having epoxy content of $2 \mathrm{~mol} / \mathrm{kg}$, oil content of $39 \%$ was synthesized at the LRNRM, ITT. 4,4'-diamino diphenylmethane of $\mathrm{P}$ grade was purchased from Aldrich, Germany. Xylene and butanol of P grade were obtained from Singapore. 


\subsection{Samples preparation}

The investigated systems were prepared by thorough mixing of different proportions of the ECO and DDM (Table 1) in the mixture of xylene and butanol with the weight ratio of xylene/butanol $=60 / 40$.

Table 1. Constituent ratio of investigated systems.

\begin{tabular}{|c|c|c|}
\hline \multirow{2}{*}{$\begin{array}{c}\text { Sample } \\
\text { number }\end{array}$} & \multicolumn{2}{|c|}{ Mol ratio } \\
\cline { 2 - 3 } & Epoxy (E) & Amin (A) \\
\hline 1 & 1 & 0.5 \\
\hline 2 & 1 & 0.75 \\
\hline 3 & 1 & 1.0 \\
\hline 4 & 1 & 1.3 \\
\hline 5 & 1 & 1.6 \\
\hline
\end{tabular}

Films of the various resins shown in Table 1 were cast either on a $\mathrm{KBr}$ crystal for Infrared (IR) spectroscopy analysis, or on a glass plate for hardness measurements, gel fraction, swelling degree determination, or on steel, cuprous plates for determination of other physico-mechanical properties. The thickness of the dry film was typically $20 \mu \mathrm{m}$.

\subsection{Curing of investigated samples}

The curing of investigated samples was realized in the Memmert-unb-200 oven (Germany) at $180^{\circ} \mathrm{C}$. After definite intervals of time, the samples were taken for analysis.

\subsection{Analysis}

The analyses of investigated samples were performed at the ITT, Academy of Science and Technology (VAST).

\subsubsection{IR analysys}

The infrared spectra of the sample, before and after curing were recorded by means of an FTIR spectrophotometer (NEXUS 670 from Nicolet). The changes of the reactive functional groups during the curing were monitored quantitatively by following the variation of their characteristic IR absorption bands, using absorption band at $2929 \mathrm{~cm}^{-1}$ (saturased C-H bonds), unchanged during the curing reaction, as an internal reference $[1,6]$.

\subsubsection{Determination of the gel fraction and the swelling degree}

The gel fraction was determined by soaking the samples in the solvent mixture of xylene and butanol with the weight ratio of xylene/butanol $=60 / 40$ for $24 \mathrm{~h}$ at the room temperature. The insoluble part of the coating was recovered by filtration and dried at $40{ }^{\circ} \mathrm{C}$ to a constant weight. The gel fraction was evaluated from the weight ratio of the insoluble part to the initial sample. 
The swelling degree was calculated from the weight ratio of the swollen polymer to the dry polymer.

\subsubsection{Determination of the physico-mechanical properties}

The Persoz hardness of the cured polymer, coated onto a glass plate, was measured by means of a pendulum damping tester (model 300, Germany), according to the standard Persoz (NFT 30-016). The relative hardness of a coating was evaluated by making the ratio of its Persoz hardness to the Persoz hardness of standard glass plate which was measured to be $425 \mathrm{~s}$. The impact resistance of the coatings was determined by means of an impact tester (model 304, Germany), according to the ISO 6272. The adhesion of the coatings on the steel was evaluated by using the Elcometer Cross Hach Cutter (England) according to ISO 2409. The ranking goes from 5 (worst) to 0 (best). The flexibility of the coatings on the cuprous plate was determined by means of a flexibility tester (model $\amalg \Gamma-1$, Russian), according to the ГOCT $6806-53$.

\section{RESULTS AND DISCUSSION}

3.1. IR spectra of curable system on the base of castor oil modified epoxy resin and 4,4'diamino diphenylmethane

The IR spectra of the coatings of the system DDM/ECO having mol ratio $\mathrm{A} / \mathrm{E}=1 / 1$ before and after the curing is shown in the Fig. 1.

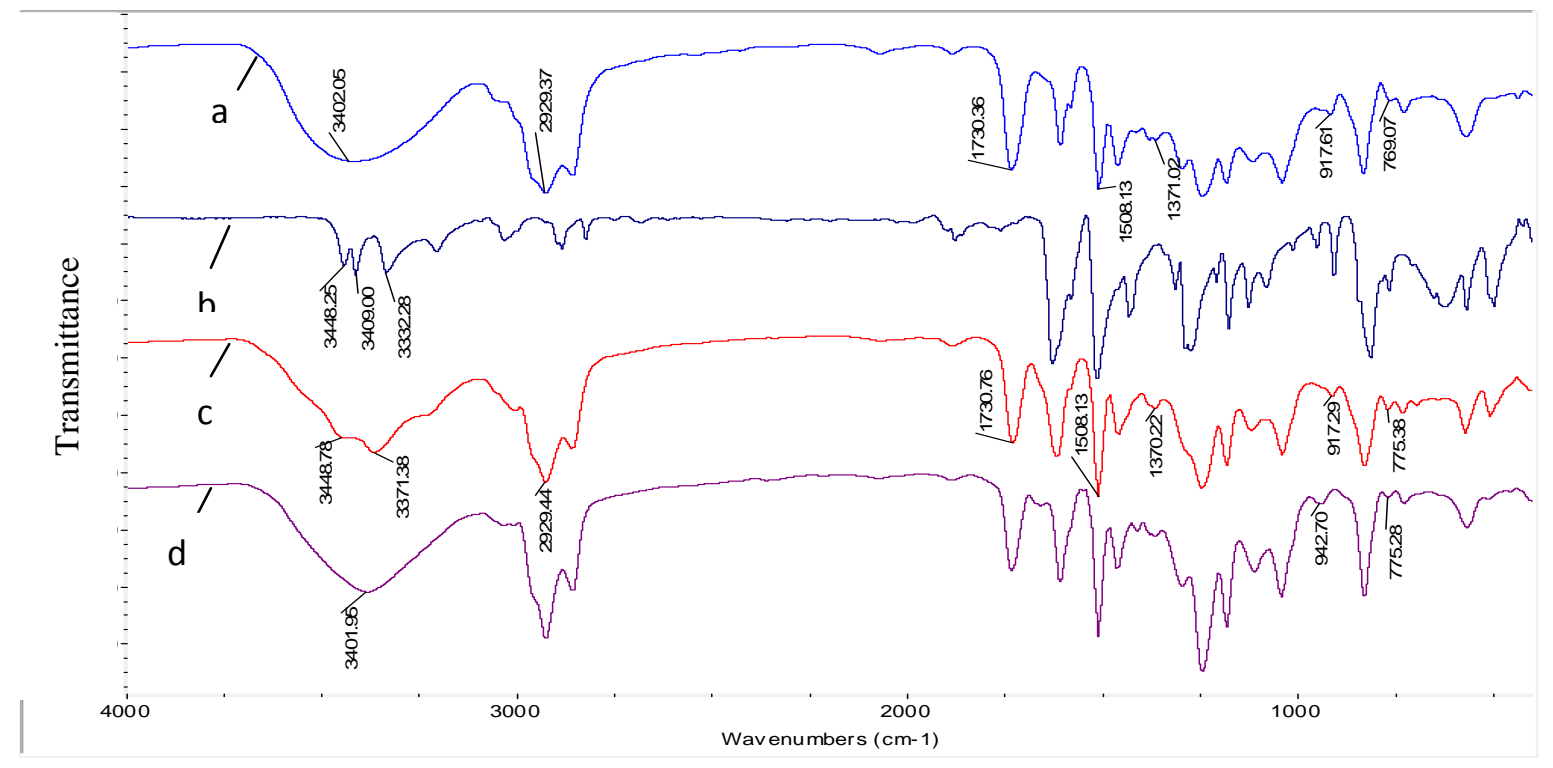

Figure 1. IR spectra of ECO (a), DDM (b) and system DDM/ECO

having mol ratio $\mathrm{A} / \mathrm{E}=1 / 1$ before (c) and after (d) 390 min curing at $180{ }^{\circ} \mathrm{C}$.

The characteristic IR absorption bands of the constituents in the investigated systems and their variations during the curing process is indicated in the Table 2. 
Table 2. Most significant IR absorption maxima of constituents, curable systems and their variation during curing process.

\begin{tabular}{|c|c|l|c|}
\hline No & Wave number $\left(\mathrm{cm}^{-1}\right)$ & \multicolumn{1}{|c|}{ Vibration } & Intensity variation \\
\hline 1 & 3448 & $-\mathrm{NH}$ stretching & Markedly reduced \\
\hline 2 & 3402 & $-\mathrm{OH}$ stretching & Increased \\
\hline 3 & 2929 & $-\mathrm{CH},-\mathrm{CH}_{2}-$ and $-\mathrm{CH}_{3}$ stretching & Unchanged \\
\hline 4 & 1730 & $\mathrm{C}=\mathrm{O}$ stretching & Unchanged \\
\hline 5 & 1508 & Stretching of aromatic double bonds & Unchanged \\
\hline 6 & 1371 & C $-\mathrm{H}$ symmetrical deformation of $-\mathrm{CH}_{3}$ groups & Unchanged \\
\hline 7 & 917 & Bending of the rings of epoxy groups & Induced \\
\hline 8 & 775 & Stretching of epoxy groups & Induced \\
\hline
\end{tabular}

It can be seen in the Fig. 1 and Table 2 that the absorption band at $2929 \mathrm{~cm}^{-1}$ (saturated C-H bands) as well as its intensity remain essentially unchanged during the curing process. The absorption bands at $917 \mathrm{~cm}^{-1}$ (ECO epoxy) and $3448 \mathrm{~cm}^{-1}$ (DDM amine) have been markedly reduced after $390 \mathrm{~min}$ curing at $180{ }^{\circ} \mathrm{C}$. Hence, the absorption bands at 917 and $3448 \mathrm{~cm}^{-1}$ were used for the quantitative evaluation of the changes in the functional groups of the coatings during their curing. The absorption band at $2929 \mathrm{~cm}^{-1}$ was used as reference for our quantitative evaluation of the reaction kinetics.

\subsection{Study of the variation of amine groups during the curing process}

The influence of the mol ratio $\mathrm{A} / \mathrm{E}$ on the conversion of amine groups during the curing process is demonstrated in Fig. 2.

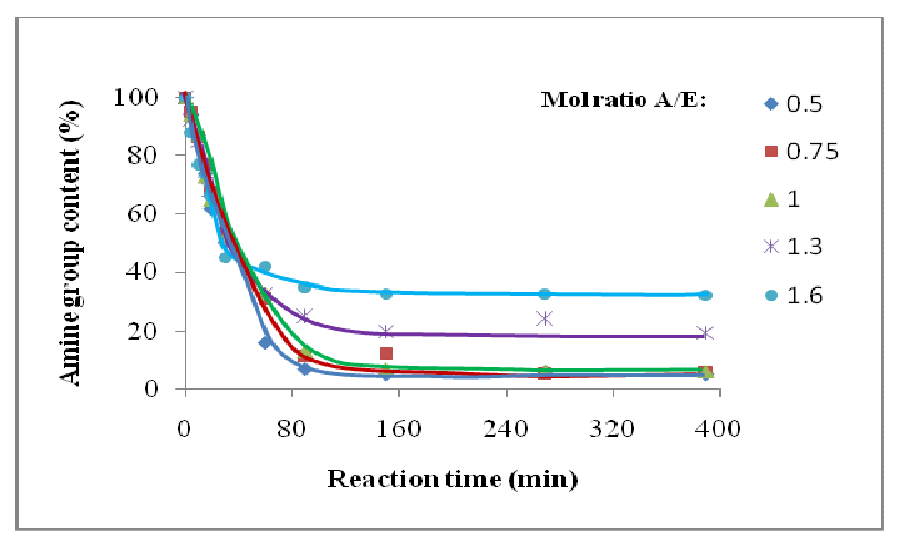

Figure 2. Variation of amine groups during the curing process. Reaction temperature $180{ }^{\circ} \mathrm{C}$.

As shown in Fig. 2, the increase of the DDM content in the investigated systems having the mol ratio A/E ranged from 0.5 to 1.6, does not affect the conversion of amine groups of the systems with various initial amine contents during the first $50 \mathrm{~min}$ of the curing process. This indicates the conversion rate of amine groups increased with the amine content. The amine groups have been almost totally converted in the coatings having the mol ratio $\mathrm{A} / \mathrm{E}$ of $0.5,0.75,1.1$ after 
100,150 and $270 \mathrm{~min}$ of the reaction, respectively. However, only 80 and $67 \%$ amine groups have been converted in the coatings with the $\mathrm{A} / \mathrm{E}$ ratio of 1.3 and 1.6, respectively, after $390 \mathrm{~min}$ of the reaction.

\subsection{Study of the variation of epoxy groups during the curing process}

The influence of the mol ratio $\mathrm{A} / \mathrm{E}$ on the conversion of epoxy groups is shown in Fig. 3.

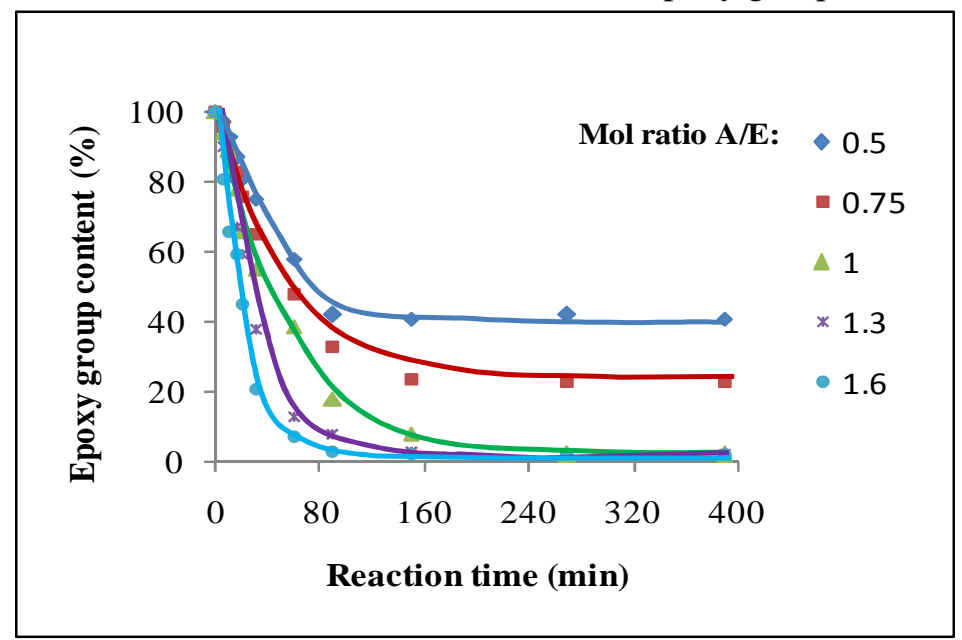

Figure 3. Variation of epoxy groups during the curing process. Reaction temperature $180{ }^{\circ} \mathrm{C}$.

It can be seen from Fig. 3 that epoxy content in investigated coatings markedly decreased during the first $30 \mathrm{~min}$ of the curing process. Then, conversion rate of epoxy groups gradually slows down. The conversion rate of epoxy groups increased with the mol ratio A/E. After 90 min of the reaction, the conversion of epoxy groups in the coatings with the mol ratio $\mathrm{A} / \mathrm{E}$ of 0.5 , $0.75,1.0,1.3$ and 1.6 reached the values of $58 \%, 67 \%, 82 \%, 92 \%$ and $97 \%$, respectively. Epoxy groups of the coatings having the ratio $\mathrm{A} / \mathrm{E}$ of $1.0,1.3,1.6$ were almost totally converted after $160-270 \mathrm{~min}$ of the reaction.

The obtained results can be explained by the reduction of the mobility of the reactive functional groups in the coatings during the curing process. At the beginning stage of the curing reaction, the formed polymer network was rather loose, the mobility of the reactive functional groups was high and curing reaction occurred rapidly. After that, the polymer network became tighter, thus, diminishing the mobility of the functional groups and reaction rate.

\subsection{Variation of relative hardness}

The variation of the relative hardness of the coatings on the base of ECO and DDM having different mol ratio A/E during the curing process is presented in Fig. 4.

As demonstrated in Fig. 4, during the first $50-150$ min of the reaction the relative hardness of investigated coatings increased with the DDM content. After that, the relative hardness of the coatings having the ratio $\mathrm{A} / \mathrm{E}$ of $0.5,0.75,1.3,1.6$ was almost unchanged, while the one having the $\mathrm{A} / \mathrm{E}$ ratio of 1.0 continued to increase, reached the value of 0.33 and was unchanged after $270 \mathrm{~min}$ of the reaction. These can be explained by the excess of amine groups in the the coatings having the ratio $\mathrm{A} / \mathrm{E}$ of 1.3 and 1.6. Similarly, the relative hardness of the coatings 
having the ratio $\mathrm{A} / \mathrm{E}$ of 0.5 and 0.75 could not increase after $75-150$ min of the reaction because of the excess of epoxy groups in the coatings.

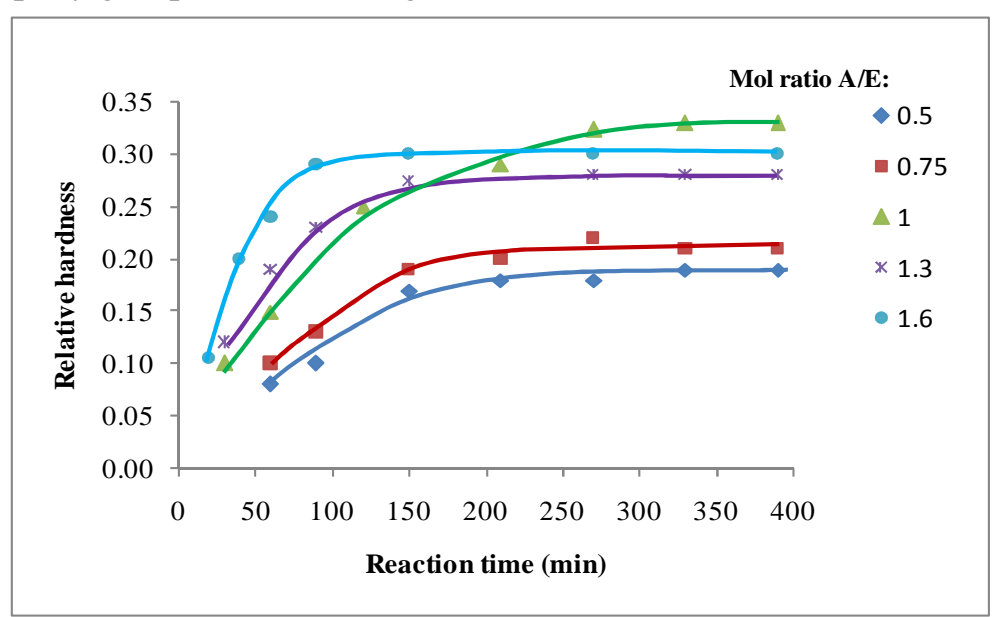

Figure 4. Variation of the relative hardness of the coatings on the base of ECO and DDM having different $\mathrm{mol}$ ratio $\mathrm{A} / \mathrm{E}$ during the curing process.

\subsection{Variation of gel fraction and swelling degree}

The variation of gel fraction and swelling degree the coating with mol ratio $\mathrm{A} / \mathrm{E}=1$ during the curing process at $180{ }^{\circ} \mathrm{C}$ is shown in Fig. 5 .

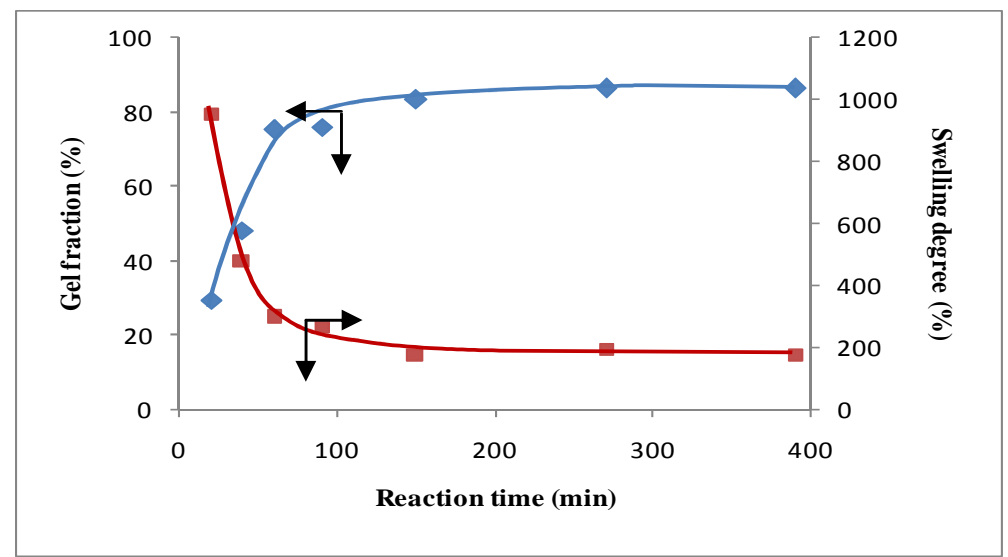

Figure 5. Variation of gel fraction and swelling degree of the coating with mol ratio $\mathrm{A} / \mathrm{E}=1$ during the curing process.

It can be seen from Fig. 5, the gel fraction of the coating increased and gained the values of $29 \%, 48 \%, 75 \%, 76 \%, 83 \%$ and $86 \%$ after 20, 40, 60, 90, 150 and $270 \mathrm{~min}$, respectively, of the curing process. Then, it was unchanged with the extension of the reaction. Accordingly, the swelling degree of the coating decreased, reached the lowest value of $188 \%$ and was unchanged after $270 \mathrm{~min}$ of the reaction. So, the coating was totally cured after $270 \mathrm{~min}$ of the reaction.

As indicated in Fig. 2 and Fig. 3, the amine and epoxy groups in the coatings having the mol values $\mathrm{A} / \mathrm{E}$ of $0.5,0.75,1.0,1.3$ and 1.6 became invariable after $150,160,270,160$ and $100 \mathrm{~min}$, respectively, of the curing reaction. The gel fraction and swelling degree of the coatings, determined at the reaction time are presented in the Table 3 . The coating with the ratio $\mathrm{A} / \mathrm{E}=1$ has 
highest gel fraction (86\%), lowest swelling degree (188\%). After $270 \mathrm{~min}$ of the curing reaction it became hard and stiff.

Table 3. Gel fraction and swelling degree of the cured coatings on the base of ECO and DDM.

\begin{tabular}{|c|c|c|c|}
\hline Mol ratio A/E & Reaction time (min) & Gel fraction (\%) & Swelling degree (\%) \\
\hline 0.5 & 150 & 67 & 192 \\
\hline 0.75 & 160 & 76 & 201 \\
\hline 1.0 & 270 & 86 & 188 \\
\hline 1.3 & 160 & 80 & 188 \\
\hline 1.6 & 100 & 78 & 268 \\
\hline
\end{tabular}

The above mentioned research results demonstrate that the optimal conditions for curing of the coatings on the base of $\mathrm{ECO}$ and DDM at $180{ }^{\circ} \mathrm{C}$ are the followings: mol ratio $\mathrm{A} / \mathrm{E}=1$, curing time 270 min.

At the optimal curing conditions, the impact resisitance, flexibility and adhesion of the coating were determined to be $200 \mathrm{kG} . \mathrm{cm}, 1 \mathrm{~mm}$ and point 1 , respectively.

\section{CONCLUSION}

Based on the research results of the study of IR spectra of the curable system containing ECO, DDM before and after the curing, the characteristic absorption bands of epoxy groups at $917 \mathrm{~cm}^{-1}$ and of amine groups at $3448 \mathrm{~cm}^{-1}$ have been chosen for quantitative determination of the groups during the curing process, using characteristic absorption band of saturated $\mathrm{C}-\mathrm{H}$ bonds at $2929 \mathrm{~cm}^{-1}$, unchanged during the reaction process, as an internal reference.

The results of the study of the variation of amine and epoxy groups; gel fraction, swelling degree and relative hardness of the coatings with various contents of amine and epoxy groups during the curing process at $180{ }^{\circ} \mathrm{C}$ showed that the cured coating with the best performance: Gel fraction of $86 \%$, swelling degree of $188 \%$, relative hardness of 0.33 , impact resistance of $200 \mathrm{kG} . \mathrm{cm}$, flexibility of $1 \mathrm{~mm}$, adhesion of point of 1 was obtained at the curing at $180{ }^{\circ} \mathrm{C}$ at the optimal conditions: mol ratio of amine and epoxy groups to be 1, reaction time $270 \mathrm{~min}$.

Acknowledgments. The authors are grateful to the financial aid of the program for support for young scientists.

\section{REFERENCES}

1. Lê Xuân Hiền - Biến đổi hóa học dầu thực vật và ứng dụng, Nhà xuất bản Khoa học tự nhiên và Công nghệ, Hà Nội, 2013.

2. Lê Xuân Hiền, Nguyễn Thị Việt Triều, Vũ Minh Hoàng, Đào Phi Hùng - Nghiên cứu đóng rắn nhựa epoxy biến tính dầu trẩu bằng 1,3 - phenylen diamin, Tạp chí Hóa học $\mathbf{5 0}$ (2) (2012) 253- 257.

3. Carbonell - Verdu A., Bernardi L., Garcia - Garcia D. , Sanches - Nacher L., Balot R. Development of environmentally friendly composite matrices from epoxidized cottonseed oil, European Polymer Journal 63 (2015) 1- 10. 
4. Ručigaj A., Alič B., Krajnc M., Šebenik U. - Investigation of cure kinetics in a system with reactant evaporation: Epoxidized soybean oil and maleic anhydride case study, European Polymer Journal 52 (2014) 105-116.

5. Facundo I. Altuna, Valeria Pettarin, Roberto J. J. Williams - Self-healable polymer networks based on the cross-linking of epoxidized soybean oil by an aqueous citric acid solution, Green Chemistry 15 (2013) 3360-3366.

6. Tarutina L. I., Pozdnhiakova F.O. - Spectrum analysis of polymers. "Chemistry", Leningrad (1986) (in Russian). 